\title{
Cost of Chronic Critically Ill Patients to the Healthcare System: A Single-center Experience from a Developing Country
}

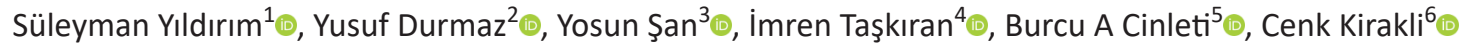

\begin{abstract}
Background: An increasing number of patients become chronic critically ill (CCI) and dependent on long-term therapies in the intensive care unit (ICU). Mortality and healthcare costs increase in these patients. In order to deal with this problem, the magnitude and risk factors for CCI must first be determined. Therefore, we aimed at evaluating the incidence cost and risk factors for CCI in our ICU.

Materials and methods: This retrospective cohort study was compiled by recruiting patients admitted to our ICU between January 1, 2017, and December 31, 2018. Patients with an ICU stay of more than 21 days were defined as CCI. Patients who did not survive in the first 21 days were excluded from the study because it could be not known whether these patients would progress to CCI. During the study period, 1,166 patients were followed up, and $475(40 \%)$ of them were excluded and 691 patients were included in the final analyses.

Results: During the study period, 691 patients were included in the study and 152 of them (22\%) were CCI. Age, acute physiology and chronic health evaluation (APACHE)-2 score, length of stay, and daily costs were higher in patients with CCI. The cost for a patient with CCl is sixfold that of a patient without CCI. ICU mortality was $47 \%$ in patients without CCI and $54 \%$ in the CCI patients $(p<0.001)$.

Conclusion: $\mathrm{CCl}$ affects an increasing number of patients and leads to increased mortality rates and cost. Prolonged duration in ICU may cause complications such as secondary infections, sepsis episodes, and acute renal injury. The treatment of these complications may lead to increased mortality and cost.
\end{abstract}

Keywords: Costs, Critical illness, Intensive care units, Renal replacement therapy, Tracheostomy.

Indian Journal of Critical Care Medicine (2021): 10.5005/jp-journals-10071-23804

\section{INTRODUCTION}

Advances in critical care medicine have lead to increased survival in more patients with an acute critical condition. Nevertheless, many of these patients become dependent on long-term support therapies. This condition is known as chronic critical illness (CCI). The description of $\mathrm{CCl}$ patients is problematic due to the lack of strict definitions. A majority of researchers have associated CCI with prolonged mechanical ventilation (PMV), because patients with PMV require longer intensive care unit (ICU) stay. ${ }^{1}$ Some investigators have proposed using tracheostomy tube placement as an indicator of PMV. Therefore, $\mathrm{CCl}$ is defined as a prolonged length of stay (LOS) in the ICU, stated as longer than 21 days, due to mechanical ventilation dependence or other intensive care treatments.

The $\mathrm{CCl}$ is characterized by prolonged LOS, increased mortality rate, and resource consumption. ${ }^{2}$ The hospital mortality was reported as $65 \%$ in some studies..$^{3,4}$ Mortality rate gradually increases after hospital discharge. ${ }^{5}$ The prevalence of CCI varies from 7 to $12 \%$ according to how $\mathrm{CCl}$ is defined. 2,6 Prolonged duration in ICU may cause complications such as secondary infections, acute kidney injury (AKI), and septic shock that can increase overall cost and mortality. ${ }^{7-9}$ Even though it appears to be a small proportion of ICU patients, the cost of healthcare for $\mathrm{CCI}$ patients appears to be high. The inhospital cost for CCI patients is over $\$ 25$ billion per year in the United States. ${ }^{10}$ Forty to sixty percentage of resources are consumed for $\mathrm{CCl}$ patients. ${ }^{2,11}$

Understanding the situation of individual hospitals and countries is vital to devising and implementing an effective action plan. To our knowledge, there are no data regarding the frequency and the cost of $\mathrm{CCl}$ in the ICUs in our country. Thus, we aimed at
1,3-6 Department of Intensive Care Unit, University of Health Sciences, Turkey, Dr Suat Seren Chest Diseases and Chest Surgery Training and Research Hospital, İzmir, Turkey

${ }^{2}$ Department of Intensive Care Unit, Hakkari Public Hospital, Hakkari, Turkey

Corresponding Author: Süleyman Yıldırım, Department of Intensive Care Unit, University of Health Sciences, Turkey, Dr Suat Seren Chest Diseases and Chest Surgery Training and Research Hospital, İzmir, Turkey, Phone: +902324333333, e-mail: deu.syldrm@gmail.com

How to cite this article: Yıldııım S, Durmaz Y, Şan Y, Taşkıran I, Cinleti BA, Kirakli C. Cost of Chronic Critically III Patients to the Healthcare System: A Single-center Experience from a Developing Country. Indian J Crit Care Med 2021;25(5):519-523.

Source of support: Nil

Conflict of interest: None

determining the rate and cost of $\mathrm{CCl}$ in our ICU and also evaluating other factors such as length of ICU stay and mortality.

\section{Materials and Methods}

This is a single-center retrospective cohort study carried out in a university-affiliated training and research center, specialized in pulmonary medicine and thoracic surgery located in the third largest city in Turkey. Our unit is a medical ICU consisting of 23 beds and 600 to 700 adult admissions per year. This study was approved by the IRB 49109414-604.02.

( ) Jaypee Brothers Medical Publishers. 2021 Open Access This article is distributed under the terms of the Creative Commons Attribution 4.0 International License (https://creativecommons.org/licenses/by-nc/4.0/), which permits unrestricted use, distribution, and non-commercial reproduction in any medium, provided you give appropriate credit to the original author(s) and the source, provide a link to the Creative Commons license, and indicate if changes were made. The Creative Commons Public Domain Dedication waiver (http://creativecommons.org/publicdomain/zero/1.0/) applies to the data made available in this article, unless otherwise stated. 


\section{Patients}

Patients admitted to the ICU between January 1,2017, and December 31, 2018, were included. Demographic data, comorbidities, APACHE-2 scores, day of tracheostomy, need for renal replacement therapy (RRT) and vasopressor treatment, and the day of ICU discharge were obtained from the hospital's electronic medical database. Patients having a LOS of more than 21 days in the ICU were defined as $\mathrm{CCl}$. Patients receiving respiratory support with an ICU LOS of at least 21 days were deemed sufficient for inclusion in the study, as in the study of Carson et al. ${ }^{1}$ Patients who did not survive in the first 21 days were excluded from the study because it could be not known whether these patients would progress to $\mathrm{CCl}$. The cost of each patient was obtained from the hospital bill, and indirect costs were not included in the analyses.

\section{Statistical Analyses}

The continuous data are expressed as medians within the 25th to 75th percentiles, and the categorical data are expressed with numbers with percentages. Normality of the data was evaluated with the Kolmogorov-Smirnov test. Continuous variables were compared by Mann-Whitney $U$ test, and categorical variables were compared by Chi-square test. Logistic regression analysis was performed to evaluate the risk factors associated with $\mathrm{CCl}$. A p value smaller than 0.05 was considered as statistically significant.

\section{Results}

During the study period, 1,166 patients were followed up in the ICU of them, 475 (40\%) were excluded because they did not survive the first 21 days in ICU. Totally 691 patients were analyzed, and 152 of them (22\%) were CCI.

The $\mathrm{CCI}$ patients were older, had higher APACHE-2 scores, and had a longer length of hospital stay before the ICU admission. Comorbidities such as chronic obstructive pulmonary disease (COPD), malignancy, congestive heart failure (CHF), and neurological diseases differed among patients with and without $\mathrm{CCl}$. The need for vasopressor drugs and RRT in patients with $\mathrm{CCl}$ was $73 \%$ and $22 \%$, respectively $(p<0.001)$ (Table 1$)$.

Table 1: Clinical and demographic characteristics of patients with and without chronic critical illness

\begin{tabular}{|c|c|c|c|c|}
\hline & Non- $\mathrm{CCl}(n=539)$ & $\mathrm{CCl}(n=152)$ & Total $(n=691)$ & $p$ \\
\hline Age (years) & $67(57-76)$ & $71(62-79)$ & $68(59-77)$ & 0.019 \\
\hline Male gender & $354(65.7 \%)$ & 99 (65.1\%) & $453(66.2)$ & 0.27 \\
\hline \multicolumn{5}{|l|}{ Comorbidities } \\
\hline COPD & $333(61.8 \%)$ & $80(52.6 \%)$ & $413(59.8 \%)$ & 0.027 \\
\hline Hypertension & 187 (34.7\%) & $48(31.6 \%)$ & $235(34 \%)$ & 0.49 \\
\hline Diabetes mellitus & $125(23.2 \%)$ & $30(19.4 \%)$ & $155(22.4 \%)$ & 0.44 \\
\hline Congestive heart failure & $138(25.6 \%)$ & $26(17.1 \%)$ & $164(23.7 \%)$ & 0.031 \\
\hline Any malignancy & $93(17.3 \%)$ & 39 (25.7\%) & $132(19.1 \%)$ & 0.026 \\
\hline Tuberculosis & $18(3.3 \%)$ & $11(7.2 \%)$ & $29(4.1 \%)$ & 0.041 \\
\hline Interstitial pulmonary disease & $11(2.0 \%)$ & $4(2.7 \%)$ & $15(2.2 \%)$ & 0.75 \\
\hline Neurological disease & $56(10.4 \%)$ & $33(21.7 \%)$ & 89 (12.79\%) & 0.001 \\
\hline \multicolumn{5}{|l|}{ Admission diagnosis } \\
\hline Exacerbation of COPD & $225(86.2 \%)$ & $36(13.8 \%)$ & 261 & \\
\hline Hypoxemic respiratory failure & $122(76.7 \%)$ & $37(23.3 \%)$ & 159 & \\
\hline Pneumonia & $110(68.3 \%)$ & $51(31.7 \%)$ & 161 & \\
\hline Sepsis & 31 (72.1\%) & $12(27.9 \%)$ & 43 & \\
\hline Pulmonary embolism & 30 (100\%) & 0 & 30 & \\
\hline Post-CPR & $6(35.3 \%)$ & $11(64.7 \%)$ & 17 & \\
\hline Postoperative & $7(77.8 \%)$ & $2(22.2 \%)$ & 9 & \\
\hline Palliative & $5(62.5 \%)$ & $3(27.5 \%)$ & 8 & \\
\hline Toxicity & $3(100 \%)$ & 0 & 3 & \\
\hline \multicolumn{5}{|l|}{ Source of ICU admission } \\
\hline Emergency service & $375(43.2 \%)$ & 70 (46.1\%) & $445(43.6 \%)$ & \\
\hline Hospital wards & $383(44.4 \%)$ & $54(35.5 \%)$ & $437(43.1 \%)$ & \\
\hline Other hospital & $48(5.6 \%)$ & $14(9.2 \%)$ & $62(6.1 \%)$ & \\
\hline Other ICU & $43(5.0 \%)$ & $11(7.2 \%)$ & $54(5.3 \%)$ & \\
\hline Operating room & $14(1.6 \%)$ & $3(2.0 \%)$ & $17(1.7 \%)$ & \\
\hline Previous ICU stay (days) & $1(1-5)$ & $2(0-9)$ & $1(1-5)$ & 0.002 \\
\hline APACHE-2 score & $16(13-20)$ & $20(16-25)$ & $18(14-23)$ & 0.001 \\
\hline Vasopressor drugs & 59 (10.9\%) & $111(73 \%)$ & $170(24.6 \%)$ & $<0.001$ \\
\hline RRT & $23(4.3 \%)$ & 33 (21.7\%) & $56(8.1 \%)$ & $<0.001$ \\
\hline Tracheostomy & $20(3.7 \%)$ & 77 (50.7\%) & $97(14 \%)$ & $<0.001$ \\
\hline LOS of ICU (days) & $6(4-9)$ & $31(25-48)$ & $7(5-14)$ & $<0.001$ \\
\hline
\end{tabular}

APACHE-2, acute physiology and chronic health evaluation; $\mathrm{CCl}$, chronic critical illness; COPD, chronic obstructive pulmonary disease; CPR, cardiopulmonary resuscitation; ICU, intensive care unit; LOS, length of stay; RRT, renal replacement therapy. Data are shown as $n$ (\%) and median (interquartile range) 
The presence of comorbidities such as COPD, malignancy, CHF, neurological diseases, vasopressor drug use, RRT, age, APACHE-2 score, and pulmonary embolism (PE) at admission were analyzed with a logistic regression model in order to determine the factors that have the greatest impact on the development of $\mathrm{CCl}$. The patients in need of vasopressors had the greatest risk of developing $\mathrm{CCl}$ odds ratio (OR) of 20.75 [95\% confidence interval $(\mathrm{Cl}), 12.49$ 34.49]. Advanced age, higher APACHE-2 score, and concomitant neurological diseases were the other risk factors for developing $\mathrm{CCl}$. Presence of COPD, CHF, and PE at admission reduced the development of $\mathrm{CCI}$ (Table 2).

LOS of patients with CCI was 31 (25-48) days and 6 (4-9) days for patients without $\mathrm{CCl}$. The daily cost and total cost for patients with $\mathrm{CCl}$ were higher than for patients without $\mathrm{CCI}(p<0.001)$. The total cost for non-CCl patients was 3850000 TL $(\$ 9160000)$ and 6850000 TL $(\$ 1620000)$ for CCl patients in 2 years $(p<0.001)$ (Table 3$)$.

Half of the patients with $\mathrm{CCl}$ were tracheostomized, and the median day of tracheostomy was day 16 (9-22). ICU mortality was $46.8 \%$ in patients who stayed in the ICU for less than 21 days and $54 \%$ in CCl patients $(p<0.001)$. Patients with CCl were mostly discharged to the pulmonary ward from the ICU (29.7\%, Table 4).

\section{Discussion}

The main finding of this study was that $\mathrm{CCl}$ patients had a higher mortality and greater costs than non-CCl patients, despite their lower prevalence. Advanced age, higher disease severity score, and presence of neurological disease at admission were found to

Table 2: Result of logistic regression analyses for development of chronic critical illness

\begin{tabular}{lcc}
\hline & Adjusted OR $(95 \% \mathrm{Cl})$ & $p$ \\
\hline Age & $1.02(1.002-1.040)$ & 0.029 \\
APACHE-2 & $1.05(1.017-1.097)$ & 0.005 \\
COPD & $0.51(0.301-0.896)$ & 0.018 \\
CHF & $0.36(0.192-0.685)$ & 0.002 \\
Malignancy & $1.53(0.835-2.819)$ & 0.16 \\
Neurological disease & $2.05(1.018-4.130)$ & 0.044 \\
Pulmonary embolism & $0.20(0.54-0.780)$ & 0.02 \\
Vasopressor drugs & $20.75(12.492-34.439)$ & $<0.001$ \\
RRT & $1.99(0.939-4.254)$ & 0.07 \\
\hline
\end{tabular}

APACHE-2, acute physiology and chronic health evaluation; CHF, congestive heart failure; COPD, chronic obstructive pulmonary disease; $\mathrm{RRT}$, renal replacement therapy

Table 3: Cost of patients with and without chronic critical illness

\begin{tabular}{lccl}
\hline & Non-CCI & CCI & $p$ \\
\hline Total cost (TL) & $5697(3625-9099)$ & $34089(25400-50597)$ & $<0.001$ \\
$\begin{array}{l}\text { Daily cost } \\
\text { (TL) }\end{array}$ & $928(859-996)$ & $1020(956-1099)$ & $<0.001$ \\
LOS of ICU & $6(4-9)$ & $31(25-48)$ & $<0.001$ \\
(days) & & $82(54 \%)$ & $<0.001$ \\
ICU mortality & $471(46.8 \%)$ & $77(50.7 \%)$ & $<0.001$ \\
Tracheostomy & $32(3.2 \%)$ & &
\end{tabular}

$\mathrm{CCl}$, chronic critical illness; ICU, intensive care unit; LOS, length of stay; $\mathrm{TL}$, Turkish Lira. Data are shown as $n(\%)$ and median (interquartile range); ${ }^{*} 1$ Turkish Lira $\simeq 0.20 \$$
Table 4: Discharge destination of patient with chronic critical illness

\begin{tabular}{lc}
\hline Discharge destination & $\mathrm{CCl}(n=70)$ \\
Hospital ward & $45(64 \%)$ \\
Palliative care unit & $15(21 \%)$ \\
Other healthcare center & $8(12 \%)$ \\
Home & $2(3 \%)$ \\
\hline
\end{tabular}

Data are shown as $n$ (\%)

be related with $\mathrm{CCl}$. Requirement of vasopressor drugs is the most important indicator for the development of $\mathrm{CCl}$.

The cost of a CCl patient was sixfold that of a non-CCl patient, and the LOS of a CCl patient was fivefold that of a non-CCl patient. The total cost for non-CCl patients (78\% of all patients) is almost half of the cost for $\mathrm{CCl}$ patients, which constitutes only $22 \%$ of patients. The main reason for this situation is that the daily cost of $\mathrm{CCl}$ patients is higher than non-CCl patients. Extended stay in the ICU might cause more infectious episodes and a higher rate of sepsis. Therefore, these patients generally need more complicated treatments such as vasopressor drugs and RRT., 9,12 In the current study, the requirement of vasopressors and RRT was more profound in patients with $\mathrm{CCl}$. The treatment of such complications due to prolonged hospitalization may increase the cost.

The prevalence of $\mathrm{CCl}$ varies between 7 and $12 \%$ in mixed ICUs (surgical and medical ICU). ${ }^{6,10}$ The prevalence of CCI was 33\% in patients with de novo acute respiratory failure in a respiratory ICU..$^{13}$ Although our study population was similar to the population of the above study, the prevalence of $\mathrm{CCl}$ was lower in our patients (22 vs 33\%). This could be attributed to the possibility of our patient population being less severe than the patient population of the aforementioned study. The main characteristic feature of $\mathrm{CCl}$ is prolonged need for respiratory support. Regardless of the underlying cause, it could be presumed that the prevalence of $\mathrm{CCl}$ is higher in ICUs where invasive mechanical ventilation is used more frequently.

In univariate analyses, age, APACHE-2 score, comorbid disease (such as COPD, CHF), neurological diseases, vasopressor drug use, and RRT were associated with development of $\mathrm{CCl}$. These variables were included in the multivariate analyses to determine which variable was an independent factor for $\mathrm{CCl}$. The need for vasopressor drugs during stay in the ICU has the highest OR $20.75(95 \% \mathrm{Cl}, 12.49-34.49)$. This finding is consistent with previous studies' results. ${ }^{13,14}$ Treatment with vasopressors is a cause of weaning failure and contributes to PMV. ${ }^{15,16}$ In addition, extended use of vasopressor drug is itself one of the long-term support therapies. As a result, administration of vasopressor agents is one of the most important predictors of development of $\mathrm{CCl}$.

Previous studies have revealed that comorbid diseases were not associated with $\mathrm{CCl}$ except neurological diseases (such as neurodegenerative diseases, stroke, paraplegia, or hemiplegia). Our findings were consistent with these studies, and we also verified that the presence of neurological diseases is a risk factor for $\mathrm{CCl}^{10,17}$ This result is not a surprise because patients with such diseases are prone to needing healthcare before being admitted to ICU. In addition, neurological diseases have a long recovery time and are relatively less lethal if provided modern support care. On the other hand, in the presence of COPD and CHF, the risk of development of $\mathrm{CCl}$ is low. Acute respiratory failure due to these two conditions 
is relatively benign, and noninvasive mechanical ventilation reduces both the need for invasive mechanical ventilation and LOS in ICU. ${ }^{18,19}$ Also, prophylactic noninvasive ventilation increases weaning success. ${ }^{20-22}$

Another interesting finding of this study was that patients with pulmonary embolism or toxicity at admission did not progress to $\mathrm{CCl}$. Both pulmonary embolism and toxicity are acute conditions which respond well to therapy. ${ }^{23,24}$ This might be the reason for these results.

Previous studies revealed that ICU mortality is higher in patients with $\mathrm{CCl}^{2,17}$ High mortality could be expected in patients with higher APACHE-2 scores. However, the difference in APACHE-2 scores between the two groups was not high enough to explain this situation. Increased mortality in $\mathrm{CCl}$ patients appears to be due to the complexity in their processes.

In our study, median LOS in CCI patients was 31 days. LOS in ICU in patients with $\mathrm{CCl}$ ranged between 15 and 44 days. ${ }^{6,14,17}$ Seventy patients (46\%) with CCI were discharged from ICU. These patients were, mostly, discharged to hospital wards. Longer LOS in ICU is associated with not only the clinical condition but also the lack of intermediate ICUs. ${ }^{25}$ Prolonged ICU stay is a major problem, and it is mostly due to the lack of downstage or hospice units in our country. Two patients (3\%) were discharged from ICU to home. Some studies report a discharge rate to home of around $22 \%{ }^{26}$ This portion was lower in our study. This result may be caused by unrealistic expectations of patients' relatives and fears about caring for these patients at home.

Prolonged ICU stay increases costs and causes inappropriate ICU bed occupancy. If patients with $\mathrm{CCl}$ could be properly discharged from ICU, the resources spent on patients could be redirected to the other patients who require acute critical care treatment.

This study has some limitations. First, it was performed in a single center and most patients were admitted for medical conditions, so these results cannot be generalized. Second, the definition of $\mathrm{CCl}$ in terms of duration varies between studies and this may have had an impact on our results. Last but not least, due to the retrospective nature, there might be some common threats to the internal validity of the study.

Our study is one of the first studies in Turkey that provides information on $\mathrm{CCl}$ in developing countries, despite the known limitations. Most of our patients have a respiratory disease such as COPD, lung cancer, and interstitial pulmonary disease, so our results give an insight into progression to $\mathrm{CCl}$ in respiratory diseases.

\section{Conclusion}

$\mathrm{CCl}$ is a serious problem with high cost and mortality. Intensive care training has improved greatly in the last decade with fellowship programs in Turkey. Hence, we primarily focus on the treatment of acute critical conditions, and patients cannot be easily discharged from the ICU due to the lack of long-term care facilities in our country. For the proper utilization of healthcare resources, many things must be considered in relation to $\mathrm{CCl}$. Having appropriate down-step units to which patients can be discharged and discharging them from the ICU as soon as safely possible are as important as the treatment of the acute condition for which they were originally admitted.

\section{OrCID}

Süleyman Yıldırım 이 https://orcid.org/0000-0001-9856-3431

Yusuf Durmaz @ https://orcid.org/0000-0002-3455-2722

Yosun Şan @ https://orcid.org/0000-0001-7167-6639

Imren Taşkıran (1) https://orcid.org/0000-0002-6166-7496

Burcu A Cinleti 으 https://orcid.org/0000-0003-3369-6617

Cenk Kirakli @ i https://orcid.org/0000-0001-6013-7330

\section{References}

1. Carson SS, Bach PB. The epidemiology and costs of chronic critical illness. Crit Care Clin 2002;18(3):461-476. DOI: 10.1016/s07490704(02)00015-5.

2. Loss SH, Marchese CB, Boniatti MM, Wawrzeniak IC, Oliveira RP, Nunes $\mathrm{LN}$, et al. Prediction of chronic critical illness in a general intensive care unit. Rev Assoc Med Bras 2013;59(3):241-247. DOI: 10.1016/ j.ramb.2012.12.002.

3. Loss SH, De Oliveira RP, Maccari JG, Savi A, Boniatti MM, Hetzel $M P$, et al. The reality of patients requiring prolonged mechanical ventilation: a multicenter study. Rev Bras Ter Intensiva 2015;27(1):2635. DOI: 10.5935/0103-507X.20150006.

4. Loss SH, Nunes DSL, Franzosi OS, Salazar GS, Teixeira C, Vieira SRR. Chronic critical illness: are we saving patients or creating victims? Rev Bras Ter Intensiva 2017;29(1):87-95. DOI: 10.5935/0103-507X.20170013.

5. Bigatello LM, Stelfox HT, Berra L, Schmidt U, Gettings EM. Outcome of patients undergoing prolonged mechanical ventilation after critical illness. Crit Care Med 2007;35(11):2491-2497. DOI: 10.1097/ 01.CCM.0000287589.16724.B2.

6. Estenssoro E, Reina R, Canales HS, Saenz MG, Gonzalez FE, Aprea MM, et al. The distinct clinical profile of chronically critically ill patients: a cohort study. Crit Care 2006;10(3):1-9. DOI: 10.1186/cc4941.

7. Gould C V., Rothenberg R, Steinberg JP. Antibiotic resistance in longterm acute care hospitals: the perfect storm. Infect Control Hosp Epidemiol 2006;27(9):920-925. DOI: 10.1086/507280.

8. Kalb TH, Lorin S. Infection in the chronically critically ill: unique risk profile in a newly defined population. Crit Care Clin 2002;18(3):529552. DOI: 10.1016/s0749-0704(02)00009-x.

9. Cabrera-Cancio MR. Infections and the compromised immune status in the chronically critically ill patient: prevention strategies. Respir Care 2012;57(6):979-990. DOI: 10.4187/respcare.01621.

10. Kahn JM, Le T, Angus DC, Cox CE, Hough CL, White DB, et al. The epidemiology of chronic critical illness in the United States. Crit Care Med 2015;43(2):282-287. DOI: 10.1097/CCM.0000000000000710.

11. Zilberberg MD, De Wit M, Pirone JR, Shorr AF. Growth in adult prolonged acute mechanical ventilation: implications for healthcare delivery. Crit Care Med 2008;36(5):1451-1455. DOI: 10.1097/ CCM.0b013e3181691a49.

12. Kao KC, Hu HC, Fu JY, Hsieh MJ, Wu YK, Chen YC, et al. Renal replacement therapy in prolonged mechanical ventilation patients with renal failure in Taiwan. J Crit Care 2011;26(6):600-607. DOI: 10.1016/j.jcrc.2011.03.005.

13. Marchioni A, Tonelli R, Sdanganelli A, Gozzi F, Musarò L, Fantini $\mathrm{R}$, et al. Prevalence and development of chronic critical illness in acute patients admitted to a respiratory intensive care setting. Pulmonology 2020;26(3):151-158. DOI: 10.1016/j.pulmoe.2019.09.006.

14. Jeffcote T, Foong M, Gold G, Glassford N, Robbins R, Iwashyna TJ, et al Patient characteristics, ICU-specific supports, complications, and outcomes of persistent critical illness. J Crit Care 2019;54:250-255. DOI: 10.1016/j.jcrc.2019.08.023.

15. Yildirim $\mathrm{F}, \mathrm{Karabacak} \mathrm{H}$, Kaya IO. Factors affecting weaning failure in critically-ill patients undergoing emergency gastrointestinal surgery. J Crit Intensive Care 2020;11(1):8-14. DOI: 10.37678/dcybd.2020.2199.

16. Muzaffar SN, Gurjar M, Baronia AK, Azim A, Mishra P, Poddar B, et al. Preditores, padrão de desmame e desfecho em longo prazo de pacientes com ventilação mecânica prolongada em unidade 
de terapia intensiva no norte da Índia. Rev Bras Ter Intensiva 2017;29(1):23-33. DOI: 10.5935/0103-507x.20170005.

17. Boniatti MM, Friedman G, Castilho RK, Vieira SRR, Fialkow LA. Characteristics of chronically critically ill patients: comparing two definitions. Clinics 2011;66(4):701-704. DOI: 10.1590/s180759322011000400027.

18. Keenan SP, Sinuff T, Cook DJ, Hill NS. Which patients with acute exacerbation of chronic obstructive pulmonary disease benefit from noninvasive positive-pressure ventilation? A systematic review of the literature. Ann Intern Med 2003;138(11):861-870. DOI: 10.7326/00034819-138-11-200306030-00007.

19. Masip J, Roque M, Sánchez B, Fernández R, Subirana M, Expósito $J$ A. Noninvasive ventilation in acute cardiogenic pulmonary edema: systematic review and meta-analysis. JAMA 2005;294(24):3124-3130. DOI: 10.1001/jama.294.24.3124.

20. Kulkarni A, Agarwal V. Extubation failure in intensive care unit: predictors and management. Indian J Crit Care Med 2008;12(1):1-9. DOI: 10.4103/0972-5229.40942.

21. Ferrer M, Sellarés J, Valencia M, Carrillo A, Gonzalez G, Badia JR, et al. Non-invasive ventilation after extubation in hypercapnic patients with chronic respiratory disorders: randomised controlled trial. Lancet 2009;374(9695):1082-1088. DOI: 10.1016/S0140-6736(09)61038-2.
22. Gong Y, Han X, Duan J, Huang S. Not all COPD patients benefit from prophylactic noninvasive ventilation after scheduled extubation: an exploratory study. Int J COPD 2019;14:2809-2814. DOI: 10.2147/COPD. S232339.

23. Marti C, John G, Konstantinides S, Combescur C, Sanchez O, Lankeit M, et al. Systemic thrombolytic therapy for acute pulmonary embolism: a systematic review and meta-analysis. Eur Heart J 2015;36(10):605-614. DOI: 10.1093/eurheartj/ehu218.

24. Coşkun R, Gündoğan $K$, Atağ E, Akbudak IH, Öztürk A, Güven M, et al. Predictors of mortality in critically ill patients with poisoning: a single center experience. Turkiye Klin J Med Sci 2013;33(5):1274-1282. DOI: 10.5336/medsci.2012-33098.

25. Iwashyna TJ. Patient and population - level approaches to persistent critical Illness and prolonged Intensive care unit stays. Crit Care Clin 2018;34(4):493-500. DOI: 10.1016/j.ccc.2018.06.001.

26. Damuth E, Mitchell JA, Bartock JL, Roberts BW, Trzeciak S. Longterm survival of critically ill patients treated with prolonged mechanical ventilation: a systematic review and meta-analysis. Lancet Respir Med 2015;3(7):544-553. DOI: 10.1016/S2213. 2600(15)00150-2. 